\title{
Effect of Deep Breathing on Heart Rate Variability Following Coronary Artery Bypass Graft
}

\author{
ZEINAB M. HELMY, Ph.D.*; ABEER A. FARGHALY, Ph.D.*; AYMN S. GADO, M.D.** and \\ HAIDY M. EL MOSALAMY, M.Sc.* \\ The Department of Physical Therapy for Internal Medicine, Faculty of Physical Therapy* and \\ The Department of Cardiothoracic Surgery, Faculty of Medicine**, Cairo University
}

\begin{abstract}
Background: Autonomic complications are among the most frequently reported complications after Coronary Artery Bypass Graft (CABG) surgery. However, the risk of autonomic complications and it's consequences is not equal for all patient, pre-operative, intraoperative and post-operative management modify the autonomic nervous system. HRV might assume an important role as a potential detector of autonomic system instability in the early post-operative phase in Intensive Care Unit and during hospital stay.
\end{abstract}

Aim of Study: The aim of this study was to investigate the effect of using inspiratory muscle trainer as a method of deep breathing exercises rehabilitation, on autonomic nervous system modulation by analyzing heart rate variability and on functional capacity through 6-minute walk test in phase 1 cardiac rehabilitation post coronary artery bypass graft (CA$\mathrm{BG})$.

Material and Methods: Forty male patients who underwent CABG aged from 40-60 years old and recruited from the Cardiothoracic Surgery, Kasr El-Ainy Hospital, Cairo University enrolled in that study. They were assigned into two groups: Group (A) studying group: Consisted of 30 patients, which received inspiratory muscle training by inspiratory trainer in addition to routine physiotherapy programme according to department protocol in for of, percussion, vibration, and breathing exercises). Group (B): Controlled Group: The control group consisted of 20 patients, which received routine chest physiotherapy program, percussion, vibration, and breathing exercises). Programme started at first day after weaning from mechanical ventilation and end at the day of discharge.

Results: Data obtained from two groups at the beginning of the study and after the end of the study before discharge from hospital regarding root square of successive differences between RR intervals (RMSSD) to calculate heart rate variability and 6 minute walking distance were statistically analyzed and compared within the same group and between the two groups. Group A showed a significant increase in the RMSSD, and walking distance through 6 minute compared with that of group $\mathrm{C}(p<0.05)$ within the same group, and between the

Correspondence to: Dr. Zeinab M. Helmy,

The Department of Physical Therapy for Internal Medicine, Faculty of Physical Therapy, Cairo University two groups. Using inspiratory muscle trainer in phase 1 cardiac rehabilitation post Coronary Artery Bypass Graft (CABG) is effective to enhance vagal tone through increasing heart rate variability and functional capacity.

Conclusion: Within the limitation i of the current study, it is concluded that, inspiratory muscle training as a method of deep breathing technique ay improve heartrate variability as an indicator for vagal activity, that in turn improve cardiac sympathovagal balance, it was also included that the deep breathing by inspiratory trainer will also improve functional capacity which measured by distance travelled in 6 minute walk test.

Key Words: Heart rate variability - Inspiratory trainer $C A B G$ coronary artery bypass graft.

\section{Introduction}

HRV has been shown to be effective as a predictor of risk after myocardial infarction and early warning sign of diabetic neuropathy, and vagal modulation is regarded as an important mechanism of sudden death. Recent evidences suggest that HRV analysis might predict complication seven in patients undergoing cardiac surgery and represent an important field of clinical research, and the present review summarizes the importance of HRV analysis in adult cardiac surgery and the perspectives for HRV use in current clinical practice [1].

Heart Rate Variability (HRV) provides indirect insight into autonomic nervous system tone, and has a well-established role as a marker of cardiovascular risk. Recent decades brought an increasing interest in HRV assessment as a diagnostic tool in detection of autonomic impairment, and prediction of prognosis in several neurological disorders. Both bedside analysis of simple markers of HRV, as well as more sophisticated HRV analyses including time, frequency domain and nonlinear analysis 
have been proven to detect early autonomic involvement in several neurological disorders [2].

Atrial Fibrillation (AF) is a frequent complication of Coronary Artery Bypass Grafting (CABG) with a reported incidence of 5\% to $40 \%$, this value estimated from a routine clinical and electrocardiographic follow-up is used after CABG [3] .

Pre-operative, intraoperative and post-operative management modify the autonomic nervous system, and it is known that many drugs might induce alterations in HRV [1].

Severe impairment of Cardiac Autonomous Regulation (CAR) assessed by Heart Rate Variability (HRV) has been observed post CABG. Lower HRV indicate impairment in the regulation of the heart's sinoatrial node rhythm, so, subject be less able to tolerate a perturbation in physiologic homeostasis [4]. Preliminary evidence suggests that HRV indexes may remain reduced for several months or years after $\mathrm{CABG}$ before returning to preoperative levels [4].

Atrial Fibrillation (AF) is one of the most frequent complications of cardiac surgery, affecting more than one third of patients, multiple perioperative factors have been proposed to contribute to it, including operative trauma, inflammation, elevations in atrial pressure (including that due to left ventricular diastolic dysfunction), autonomic nervous system imbalance, metabolic and electrolyte imbalances, or myocardial ischemic damage incurred during the operation [5].

The development of post-operative AF is associated with a higher risk of operative morbidity, prolonged hospitalization, and increased hospital cost compared with that in patients remaining in sinus rhythm [5].

Among all cardiovascular complications, new onset Post-Operative Atrial Fibrillation (POAF) is one of the most common complications. POAF occurs most frequently in the first 5 days after cardiac surgery, with a peak incidence on 2 nd and 3 rd day post-operative. POAF is associated with an increased risk of mortality and morbidity, leads to a higher risk of stroke, requires additional treatment, and increases post-operative costs. So, it considered a significant problem [6] .

Systemic and local inflammation due to pathophysiologic effects of Cardiopulmonary Bypass (CPB) and damage to the atrium by direct incision are unavoidable consequences of cardiothoracic procedures and contribute to the occurrence of
POAF. It is believed that surgical stress, as such, is a more significant trigger of POAF than is systemic inflammation [6].

There seems to be a significant increase in sympathetic tone in the post-operative period, in those patients who subsequently develop AF. The pre-existence of abnormal atrial tissue and electrophysiological abnormalities that may be amplified during surgery and, when subjected to an adverse post-operative triggers, could result in $\mathrm{AF}$ [7].

The first report linking HRV to respiration has been credited to Karl Ludwig, who in 1847 noted that heart rate increased with inspiration and decreased with expiration [8].

Respiratory muscle training at high intensities can promote greater parasympathetic activity and it may confer important benefits during a rehabilitation program in post-coronary artery bypass grafting. Respiratory muscle training at high intensities can promote greater parasympathetic activity and it may confer important benefits during a rehabilitation program in post-coronary artery bypass grafting [2].

The changes in heart rate associated with respiratory activity are mediated primarily by a combination of changing levels of efferent cardiac vagal and sympathetic activity and mechanically induced sinus node stretch with each respiration.

HRV during deep breathing test has shown that vagal-cardiac activity is diminished in patients with coronary artery disease.

Deep breathing produced faster, more variable HR, while shallow breathing had the opposite effects [9].

\section{Aim of study:}

The purpose will be to investigate the effect of deep breathing on heart rate variability and autonomic nervous system in cardiac rehabilitation after coronary artery bypass graft.

\section{Statement of the problem:}

DOES deep breathing will affect heart rate variability and autonomic nervous system function in cardiac rehabilitation after coronary artery bypass graft?

\section{Significance of the study:}

Many studies have invariably demonstrated that open heart surgery generally leads to significant HRV reduction, which is even more pronounced than after myocardial infarction [10] 
Ejection fraction correlates well with HRV parameters, prolonged HRV reduction following CABG can also be perceived as a reflection of the level of ejection fraction damage [10].

According to some studies HRV is superior to left ventricular ejection fraction in predicting arrhythmic events (sudden cardiac death and ventricular Tachycardia) [9].

Respiratory muscle training at high intensities can promote greater parasympathetic activity and it may confer important benefits during a rehabilitation program in post cronary artery bypass surgery [10]

\section{Subjects and Methods}

\section{I- Subjects:}

Forty male patient with age ranged from 40 to 60 years old was recruited from Cardiothoracic Surgery Department in Kasr Ainy Hospital at Faculty of Medicine, Cairo University from October 2018 to November 2019. They randomized into two groups: 30 patients in the study group (SG) and 10 patients in the control group (CG), undergoing coronary artery bypass graft via median sternotomy.

\section{Inclusion criteria:}

- Patient the anesthetic protocol and surgical technique, including the protocol for conduct of $\mathrm{CPB}$ were the same. All patients underwent median sternotomy.

- Aged from 40 to 60 years old male patients.

- Analgesia in the post-operative period was optimized and followed the standard protocol used at the hospital.

\section{Exclusion criteria:}

- Patients who did not understand the techniques used were excluded from the study.

- Those who presented hemodynamic instability during evaluations or performance of inspiratory muscle training.

- Those who have complications and readmitted to the ICU.

- Patient with previous open heart surgery.

- Patient with uncontrolled diabetes mellites.

- Patient with presurgicsal autonomic dysfunction.

Patient who spent more than 24 hours on mechanical ventilation after operation.
Patient were divided into two groups 30 patient in studying group and 10 patient in controlled group:

- Group A (studying group): Who received inspiratory muscle training in addition to post-operative routine chest physiotherapy in form of (breathing exercise, clearance techniques, early ambulation) starting from first day after mechanical ventilation weaning until the day of discharge from hospital, 2 session per day.

- Group B (controlled group): Who received postoperative routine chest physiotherapy in form of (breathing exercise, clearance technique, and early ambulation) starting from first day after mechanical ventilation weaning until the day of discharge from hospital, 2 session per day.

\section{II- Instrumentation:}

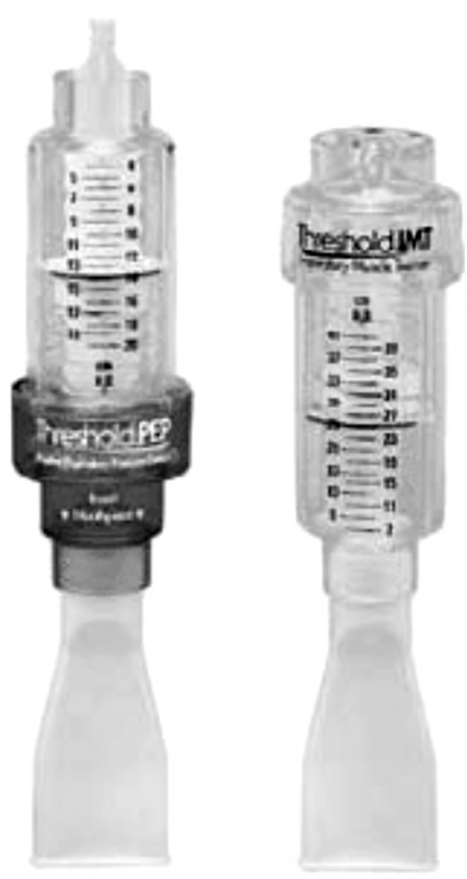

Fig. (1): IMT (Inspiratory Muscle Trainer).

The Threshold $\AA$ IMT (Respironics Inc., Murrysville, PA, USA) is an inspiratory muscle trainer, which has been widely used with various health conditions. This device contains, at its end, a valve closed by the positive pressure of a spring, which can be graded from 9 to $41 \mathrm{~cm} \mathrm{H}_{2} \mathrm{O}$ and allows resistance changes by $2 \mathrm{~cm} \mathrm{H} 2 \mathrm{O}$ increments. The Threshold IMT has a one-way spring-loaded valve, that closes during inspiration and requires that participants inhale hard enough, to open the valve and let the air enter. This device provides constant pressure for inspiratory muscle training, regardless of how quickly or slowly the participants breathe, and the optimal loading pressure can be adjusted, 
based upon the individual characteristics of the participants. Threshold IMT provides consistent and specific pressure for inspiratory muscle strength and endurance training, regardless of how quickly or slowly patients breathe. This device incorporates a flow-independent one-way valve to ensure consistent resistance and features an adjustable specific pressure setting (in $\mathrm{cm} \mathrm{H}_{2} \mathrm{O}$ ) to be set by a healthcare professional. When patients inhale through Threshold IMT, a spring-loaded valve provides a resistance that exercises respiratory muscles through conditioning [11].

From the first day after extubation from mechanical ventilator, the control group was managed according to the routine of the unit while the training group underwent daily protocol of respiratory muscle training until the day of discharge.

For safety criteria, all patients were evaluated for hemodynamic (blood pressure, heart rate and double product) and lung function (respiratory rate and oxygen saturation), before, during and after the session. If there was an increased heart rate and higher blood pressure above baseline value, session will stopped, performing 3 sets $40 \%$ of MIP, with 10 repetitions. This training was performed twice daily until hospital discharge, patients in both groups heart rate variability will evaluated through short period 2 minutes ECG, through time domain analyzed method.

\section{ECG (electro cardiograph):}

ECG the process of recording the electrical activity of the heart over a period of 2 minutes using electrodes placed on the skin. These electrodes detect the tiny electrical changes on the skin that arise from the heart muscle's electrophysiological pattern of depolarizing and repolarizing during each heartbeat, to calculate heart rate variability through time domain method, short-term heart rate variability analyses of all the patients were obtained, and time-domain indices, root-mean square differences of successive R-R intervals [RMSSD] were calculated.

Standard twelve-lead ECG and short-term HRV measurement were done after the last session on day of charge using ECG system. The evaluation was performed at rest in the supine position for a period of 2 minutes, 2 minutes being used for RR interval for recording and further analysis.

\section{III- Evaluating procedures:}

Time domain method to calculate heart rate variability: The single most common way in which to analyses HRV is a time-domain method called
RMSSD. This is the Root Mean Square of Successive Differences between each heartbeat. It is relatively simple to calculate, and provides a reliable measure of HRV and parasympathetic activity, the RMSSD reflects the beat-to-beat variance in $\mathrm{HR}$ and is the primary time-domain measure used to estimate the vagally mediated changes reflected in HRV (RMSSD) is obtained by first calculating each successive time difference between heartbeats in ms. Then, each of the values is squared and the result is averaged before the square root of the total is obtained [12]

Time domain method will be used to analyze heart rate variability early after operation at first day after weaning of mechanical ventilation, and on the day of discharge from hospital in both groups.

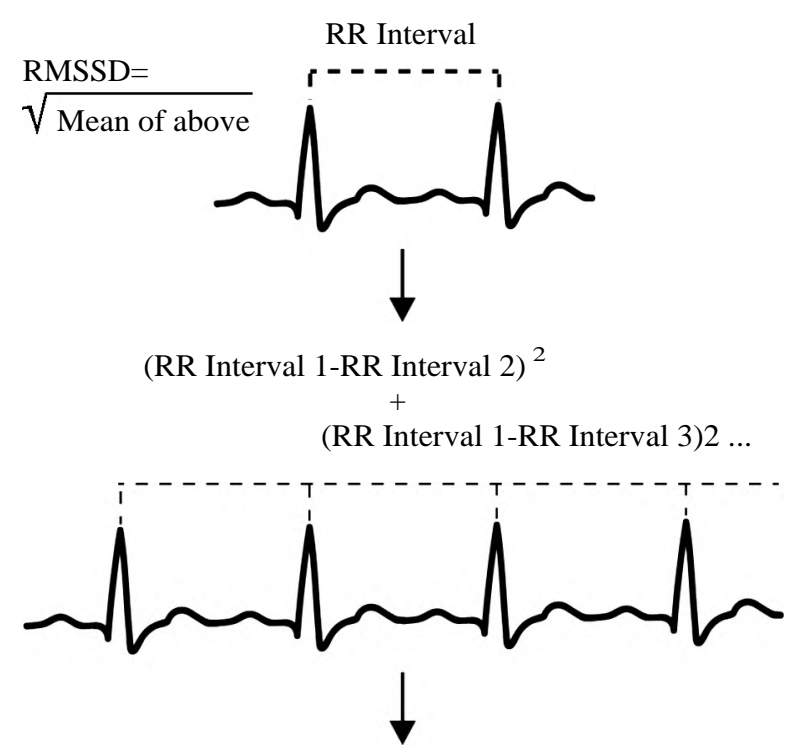

Fig. (2): Time domain method to calculate heart rate variability.

\section{Minute walk test:}

Will applied as a functional assessment early at 3 rd day post-surgery and at the last day in hospital before discharge for both groups.

The 6 MWD was applied in an in-door corridor, with little traffic of people, with proper window ventilation in its entire length.

A 30m length strip line tape was marked on the floor. In every $3 \mathrm{~m}$ there was a marking according to the recommendations of the American Thoracic Society. Before and after 6 MWD the patient was monitored by cardio, by respiratory frequency, by peripheral oxygen saturation, and blood pressure, total test time and number of rest period will be calculated test will be symptom limited, if patient sense chest pain, dizziness, or other sign, test will be stopped. 
It was applied for the predicted values and the calculation of $6 \mathrm{MWD}$, the reference equation providing an estimation of the distance in the sixminute walk test.

For male patients the estimated distance was equal to $(7.57 \mathrm{~cm} \mathrm{X}$ height $)-(5.02 \mathrm{X}$ age $)-(1.76$ $X$ weight $\mathrm{kg}$ ) $-309 \mathrm{~m}$, minus $153 \mathrm{~m}$ in order to acquire the lower standard limit.

For female the ratio was $(2.11 \mathrm{X}$ height $\mathrm{cm})-$ $(2.29 \mathrm{X}$ weight $\mathrm{kg})(5.78 \mathrm{X}$ age $)+667 \mathrm{~m}$, minus $153 \mathrm{~m}$ for the lower standard limit. The main purpose of this study was investigation of the response of heart rate variability, deep breathing test, 6 minute walk test, number of, and number of days in hospital to deep breathing training by using inspiratory muscle trainer in patients who have underwent coronary artery bypass graft.

\section{Results}

Analysis of results:

This study was designed to investigate the response of heart rate variability, and 6 minute walk test, to inspiratory muscle trainer in phase one cardiac rehabilitation in patients who have underwent coronary artery bypass graft.

ECG (electro cardiograph) was used to assess heart rate variability and number of PVCS in 40 male patients, at first day after extubating from mechanical vent elation and on the day of discharge from hospital.

Patient's demographic data, clinical characteristics and post-operative history were collected from admission record and surgical report.

The collected data for all patients who completed the procedure of the study were presented and discussed under following heading:

\section{I- Demographic data:}

In this study, 40 male patients post coronary artery bypass graft were assigned randomly into two groups, studying group (30 patients), controlled group (10 patients).

Group A (studying group): Thirty patients were included in this group, the data in table and fig. represented their median age 52 years old ranged from 41-60 years old.

Group B (controlled group): Ten patients were included in this group, the data in table and fig. represented their median age 52.5 years old, ranged from 41-59 years old. There was no significant difference between both groups in their ages where their $p$-value was 0.766 .

Table (1): Physical characteristics of patients in both groups (A, B).

\begin{tabular}{|c|c|c|c|c|c|c|c|}
\hline \multirow{2}{*}{ Item } & \multicolumn{2}{|c|}{ Group A } & \multicolumn{2}{|c|}{ Group B } & \multicolumn{2}{|c|}{ Comparison } & \multirow{2}{*}{$S$} \\
\hline & Mean & $\pm \mathrm{SD}$ & Mean & $\pm \mathrm{SD}$ & $\mathrm{Z}$-value & $p$-value & \\
\hline Age years & 50.4 & 6.3 & 51.1 & 5.9 & -0.297 & 0.76 & NS \\
\hline
\end{tabular}

A- Within studying group:

Table demonstrated the RMSSD (root mean square of successive differences between intervals), before and after training by inspiratory muscle trainer in addition to traditional physiotherapy in studying group (group A) and before and after traditional physiotherapy in controlled group (group B). There was a significant increase in wilcxonsigned-rank-test between before and after treatment in both groups, RMSSD pretreatment by inspiratory muscle trainer as median value was $(0.185)$.

And post-treatment was .8, where the z-value was $-4,763$ and $p$-value was 0,0 , while RMSSD AS a median value in controlled group was 0.16 and post-treatment was 0.35 , where the $\mathrm{z}$-value was -2.136 and $p$-value was 0.033 .

Table (2): Median, minimum, maximum, $\mathrm{z}$-value, $p$-value of RMSSD, before and after training in both groups.

\begin{tabular}{|c|c|c|c|c|}
\hline \multirow[b]{2}{*}{ RMSSD } & \multicolumn{2}{|c|}{$\begin{array}{c}\text { Group A } \\
\text { (training group) }\end{array}$} & \multicolumn{2}{|c|}{$\begin{array}{c}\text { Group B } \\
\text { (controlled group) }\end{array}$} \\
\hline & $\begin{array}{c}\text { At first } \\
\text { day after } \\
\text { extubation }\end{array}$ & $\begin{array}{c}\text { At the } \\
\text { day of } \\
\text { discharge }\end{array}$ & $\begin{array}{c}\text { At first } \\
\text { day after } \\
\text { extubation }\end{array}$ & $\begin{array}{c}\text { At the } \\
\text { day of } \\
\text { discharge }\end{array}$ \\
\hline - Median & 0.18 & 0.8 & 0.16 & 0.35 \\
\hline • Maxium & 0.7 & 0.6 & 0.7 & 1 \\
\hline - Minimum & 0 & 0 & 0 & 0 \\
\hline $\begin{array}{l}\text { - Median } \\
\text { difference }\end{array}$ & \multicolumn{2}{|c|}{0.6} & \multicolumn{2}{|l|}{0.3} \\
\hline •Z-value & \multicolumn{2}{|c|}{-4.763} & \multicolumn{2}{|c|}{-2.36} \\
\hline • $p$-value & \multicolumn{2}{|c|}{$0.00 *$} & \multicolumn{2}{|c|}{$0.003 *$} \\
\hline
\end{tabular}

N.B: *: Means this value is significant.

\section{B- Between Groups:}

Table (3) revealed the Mann-Whitney U-test for the RMSSD at first day after extubating and at day of discharge between groups $\mathrm{A}$ and $\mathrm{B}$, there was no significant difference in value at first day where $\mathrm{z}$-value was $-0,016$ and $p$-value was 0,988 .

While there was a significant difference in the value at the day of discharge, where $\mathrm{z}$-value was $-2,404$ and $p$-value was 0,016 . 
Table (3): Mann whity U-test between group A and group B, for RMSSD, at first day after extubation of mechanical ventilation, and at the day of discharge.

\begin{tabular}{|c|c|c|c|c|}
\hline \multirow[t]{2}{*}{ RMSSD } & \multicolumn{2}{|c|}{$\begin{array}{l}\text { At first day } \\
\text { after extubation }\end{array}$} & \multicolumn{2}{|c|}{$\begin{array}{l}\text { At the day } \\
\text { of discharge }\end{array}$} \\
\hline & Group & roup B & Group A & Group B \\
\hline Median & .18 & .16 & .8 & .35 \\
\hline Maxium & .7 & .7 & 1.6 & 1 \\
\hline Minimum & 0 & 0 & 0 & 0 \\
\hline Median difference & \multicolumn{2}{|c|}{.02} & \multicolumn{2}{|c|}{.45} \\
\hline Z-value & \multicolumn{2}{|c|}{-.016} & \multicolumn{2}{|c|}{-2.404} \\
\hline$p$-value & \multicolumn{2}{|c|}{.988} & \multicolumn{2}{|c|}{$.016^{*}$} \\
\hline
\end{tabular}

6-minute walk test:

A- Within studying group:

\section{Group A:}

Table (4) demonstrated the 6 minute walk test result which consider indicator to functional capacity, before and after training by inspiratory muscle trainer in addition to traditional physiotherapy in studying group, and before and after traditional physiotherapy training in controlled group. There was a significant increase in wilcxon-signedrank-test between before and after treatment in both groups, 6 minute walk test distance pretreatment in group A as median value was 60 and post-treatment was 105 , where the $\mathrm{z}$-value was $-4,78$ and $p$-value was 0,0 , while 6 minyte walk distance in controlled group as a edian value before treatment was 50 and after treatment was 80, where $\mathrm{Z}$-value was -2.820 and $p$-value was .005 .

Table (4): Median, minimum, maximum, $\mathrm{z}$-value, $p$-value of 6 minute walk test, before AND after training in both groups.

\begin{tabular}{|c|c|c|c|c|}
\hline \multirow[b]{2}{*}{$\begin{array}{l}6 \text { Minute } \\
\text { walk test }\end{array}$} & \multicolumn{2}{|c|}{ Group A } & \multicolumn{2}{|c|}{ Group B } \\
\hline & $\begin{array}{c}\text { At first } \\
\text { day after } \\
\text { extubation }\end{array}$ & $\begin{array}{c}\text { At the } \\
\text { day of } \\
\text { discharge }\end{array}$ & $\begin{array}{c}\text { At first } \\
\text { day after } \\
\text { extubation }\end{array}$ & $\begin{array}{c}\text { At the } \\
\text { day of } \\
\text { discharge }\end{array}$ \\
\hline • Median & 60 & 105 & 50 & 80 \\
\hline - Maxium & 90 & 160 & 80 & 120 \\
\hline - Minimum & 20 & 40 & 25 & 35 \\
\hline $\begin{array}{l}\text { Median } \\
\text { difference }\end{array}$ & \multicolumn{2}{|l|}{45} & \multicolumn{2}{|l|}{30} \\
\hline -Z-value & \multicolumn{2}{|c|}{-4.78} & \multicolumn{2}{|c|}{-2.820} \\
\hline •p-value & \multicolumn{2}{|c|}{$.00^{*}$} & \multicolumn{2}{|c|}{$.005^{*}$} \\
\hline
\end{tabular}

N.B: *: Means this value is significant.

\section{B- Between groups:}

Table (5) revealed the Mann-Whitney U-test for the 6 minute walk test 3 rd day after operation and at day of discharge between groups A and B, there was no significant difference in value at 3 rd day where $z$-value was $-1,11$ and $p$-value was 0,26 while there was a significant difference in the value at the day of discharge, where $\mathrm{z}$-value was $-2,21$ and $p$-value was 0,027 .
Table (5): Ann Whity U-test between group A and B for 6 minute walk test, at third day after extubation and at the day of discharge.

\begin{tabular}{lcccc}
\hline RMSSD & $\begin{array}{c}\text { At first } \\
\text { day after } \\
\text { extubation } \\
\text { Group A }\end{array}$ & $\begin{array}{c}\text { At the } \\
\text { day of } \\
\text { discharge } \\
\text { Group B }\end{array}$ & $\begin{array}{c}\text { At first } \\
\text { day after } \\
\text { extubation } \\
\text { Group A }\end{array}$ & $\begin{array}{c}\text { At the } \\
\text { day of } \\
\text { discharge } \\
\text { Group B }\end{array}$ \\
\hline - Median & 60 & 50 & 105 & 80 \\
- Maxium & 90 & 80 & 160 & 120 \\
- Minimum & 20 & 25 & 40 & 35 \\
- Median & 10 & & 25 & \\
difference & & & -2.21 & \\
- Z-value & -1.11 & & $.027 *$ & \\
- $p$-value & .26 & & &
\end{tabular}

N.B: *: Means this value is significant.

\section{Discussion}

Fourty males patients were enrolled in this study with their age ranged from 40 to 60 years old. Participants assigned into 2 groups, 30 patients in studying group, and 10 patients in controlled group. $p$-values less than 0.05 was considered statistically significant. The results of this study showed that there was significant difference in heart rate variability which measured by using time domain method between studying and controlled group.

To our knowledge few studies addressed the effect of deep breathing exercises on heart rate variability after open coronary artery bypass surgery. Our study showed a significant increase in RMSSD pre and post training by inspiratory trainer $p$-value <.05, which indicate enhancement of para sympathetic tone. A possible explanation for the increase in parasympathetic and decrease sympathetic modulation during a higher inspiratory workload is the increase in tidal volume, as well as the increase in inspiratory effort.

In this context, there is study fulfilled by Flavia, [13] demonstrated that the magnitude of autonomic responses of HR during Respiratory Sinus Arrhythmia (RSA) maneuver is directly proportional to the tidal volume, RMT could be an important strategy to enhance vagal tone in parallel to aerobic exercise training programs in these patients. In particular, the positive effects of RMT on vagal tone could produce a cardio protective effect, reducing risks to arrhythmias and fatal events.

In other hand, there is study conducted by Surekharani Chinagudi et al., [14], investigate the effect of short term deep breathing exercises on heart rate variability, this study observed slow deep breathing for five minutes shifted the cardiac autonomic balance towards sympathetic nervous 
system. This is because when body begins a new exercise for the first time, it is always the sympathetic nervous system that gets activated.

In other randomized controlled trial study conducted by Tharion E, et al., [15] on healthy subjects, neither the mean of the RR intervals nor the parameters reflecting sympatho-vagal balance were significantly different across the groups. This findings may be attributed to the fact that the study conducted on healthy subject, also, the age group in that study was (21-33) years old which different from the age group of present study (40-60) years old, which accompanied by differences in autonomic nervous system modulation.

This study showed significant difference in 6 minute walk test between two groups and within the group $p$-value <.05, the distance travelled by the patient increased after deep breathing training due to increase lung volumes by training and reduce atelectasis, improve ventelation perfusion matching which leads to increase functional work capacity.

This result supported by (Monisha R, and TS Muthukumar, 2018) [16] who studied the effect of active cycle of breathing exercise on 6 minute walk test as an indictor of functional capacity post coronary artery by pass graft surgery.

They concluded that pre-and post-operative 6 MWT distances were shown significant difference; chest expansion following $\mathrm{CABG}$ has attained a near normal value following ACBT at the end of treatment.

At other hand, there is study produce by Savc1 S, et al., [17] they investigate the effect of active cycle of breathing techniques and incentive spirometer in coronary artery bypass graft surgery, on lung function and 6 minute walk test insixty male patient (40-71) years old devided into groups group trained with active cycle of breathing technique and other group trained with incentive spirometry, they reported that no significant differences were found in $6 \mathrm{MWT}$ distance, percentage of predicted distance, heartrate, and oxygen saturation performed before and after deep inspiratory training on the fifth day following CABG surgery between the groups $(p>0.05)$. In the current study we found significant difference in distance travelled in 6 minutes between the controlled group who received traditional physiotherapy, and studying group who received inspiratory muscle training at $40 \%$ of MIP, difference in results between two studies almost du to differentiation in training programme duration, study which showed there is no significant difference had 5 days only in training according to hospital protocol, current study consumed longer period in training.

\section{Conclusion:}

Within the limitation of the current study, it is concluded that inspiratory muscle training following $\mathrm{CABG}$ coronary artery bypass graft as a method of deep breathing technique improve heart rate variability as an indicator for vagal activity, that in turn improve cardiac sympathovagal balance, also it was concluded that the deep breathing with inspiratory trainer will also improved as measured by 6 minute walking test.

\section{References}

1- ANTONIO NENNA, MARIO LUSINI, CRISTIANO SPADACCIO, FRANCESCO NAPPI, SALVATORE MATTEO GRECO, RAFFAELE BARBATO, ELVIO COVINO, and MASSIMO CHELLO: Heart rate variability: A new tool to predict complications in adult cardiac surgery, J. Geriatr. Cardiol., Nov., 14 (11): 662-8, 2017.

2- IWONA CYGANKIEWICZ and, WOJCIECH ZAREBA: Heart rate variability, Handbook of Clinical Neurology, Volume 117, Pages 379-3933, 2013.

3- ASHRAF MOSTAFA, MOHAMED A. EL-HADDAD, MAITHILI SHENOY, and TUSHAR TULIANI: Atrial fibrillation post cardiac bypass surgery, Avicenna J. Med., Jul.-Sep., 2 (3): 65-70, 2012.

4- RENATA GONCALVES MENDES, RODRIGO POLAQUINI SIMOES, FERNANDO De SOUZA MELO COSTA, CAMILA BIANCA FALASCO PANTONI, LUCIANA Di THOMMAZO, SÉRGIO LUZZI, APARECIDA MARIA CATAI and ROSS ARENA: Short-term supervised inpatient physiotherapy exercise protocolimproves cardiac autonomic function after coronary artery bypass graftsurgery-a randomised controlled trial, Disability and Rehabilitation, 32 (16): 1320-7, 2010.

5- HOGUE C.W. Jr.1, CRESWELL L.L., GUTTERMAN D.D. and FLEISHER L.A.: American College of Chest Physicians, Epidemiology, mechanisms, and risks: American College of Chest Physicians guidelines for the prevention and management of postoperative atrial fibrillation after cardiac surgery, US National Library of Medicine National Institutes of Health, Aug., 128 (2 Suppl): 9S16S, 2005.

6- VLADIMIR V. LOMIVOROTOV*, LOMIVOROTOV, SERGEY M. EFREMOV, M.D., Ph.D.*, EUGENIY A. POKUSHALOV and ALEXANDER M. KARASKOV: New-Onset Atrial Fibrillation After Cardiac Surgery: Pathophysiology, Prophylaxis, and Treatment, January Volume 30, Issue 1, Pages 200-16, Doi: https:// doi.org/ 10.1053/j.jvca.2015.08.003, 2016.

7- RAMÓN RODRIGO1: *Prevention of Post-operative Atrial Fibrillation: Novel and Safe Strategy Based on the Modulation of the Antioxidant System, Front Physiol. GY.3; 2012PMC332503.

8- ROBERT W. SHIELDS, J.R., M.D.: Neuromuscular Center, Neurological Institute, cleveland Clinic Journal OF Medicine Volume 76o, Supplement 2, 2009. 
9- M. TAMOSIUNAITE, G. URBONAVICIEN, A. VAINORAS, G. GARGASAS, S. KAMINSKIENE, SUKILELIU A.V., LITHUANIAI. BLUZAITE and H. RICKLI: Influence of Deep Breathing on Heart Rate Variability in Patients with Ischemic Heart Disease, Medicinos Technologija, Nr. 3 (59), 2005.

10- NENAD L., 1 DARIJA M., PETER K., et al.: Changes in Heart Rate Variability after Coronary Artery Bypass Grafting and Clinical Importance of These Findings. September, 14. Volume 2015, Article ID 680515, 7 pages, 2014.

11-A. MOLASSIOTIS, A. CHARALAMBOUS, P. TAYLOR, Z. STAMATAKI and Y. SUMMER: The effect of resistance inspiratory muscle training in the management of breathlessness in patients with thoracicmalignancies: A feasibility randomised trial, Springer-Verlag Berlin Heidelberg, 10 November, 2014.

12- SHAFFER F.1 and GINSBERG J.P.2: An Overview of Heart Rate Variability Metrics and Norms, Front Public Health. Sep. 28, 5: 258. Doi: 10.3389/fpubh.2017.00258. 2017.

13- FLAVIA C.R., RODRIGO P.S., MICHEL S.R., et al.: High-Intensity Inspiratory Protocol Increases Heart Rate
Variability in Myocardial R evascularization Patients. Braz. J. Cardiovasc. Surg., Jan.-Feb., 31 (1): 38-44, 2016.

14- SUREKHARANI CHINAGUDI, SUKANYA BADAMI, ANITA HERUR, SHAILAJA PATIL, SHASHIKALA G.V., and ROOPA ANKAD: Immediate effect of short duration of slow deepbreathing on heart rate variability in healthy adults, National Journal of Physiology, Pharmacy \& Pharmacology| Vol. 4 | Issue 3 | 233-5, 2014.

15-THARION E., SAMUEL P., RAJALAKSHMI R., GNANASENTHIL G. and SUBRAMANIAN R.K.: Influence of deep breathing exercise on spontaneous respiratory rate and heart rate variability: A randomised controlled trial in healthy subjects, Indian Journal of Physiology and Pharmacology, Jan.-Mar., 56 (1): 80-7, 2012.

16- MONISHA R. and T.S. MUTHUKUMAR: Efficacy of Active Cycle of Breathing Technique on Functional Improvement in Post CABG Patient, Research in Medical \& Engineering Sciences, 05.000602, 2018.

17- SAVC S., SAKNÇ S., INAL INCE D., ARKAN H., CAN Z., BURAN Y. and KURALAY E.: Active cycle of breathing techniques and incentive spirometer incoronary artery bypass graft surgery, Fizyoterapi Rehabilitasyon, 17 (2): 61-9, 2006.

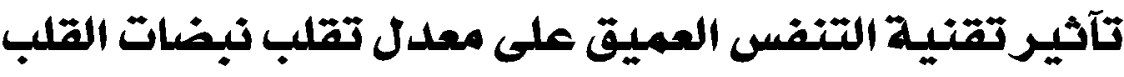

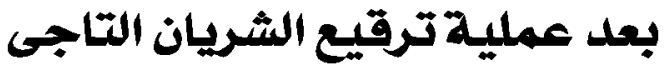

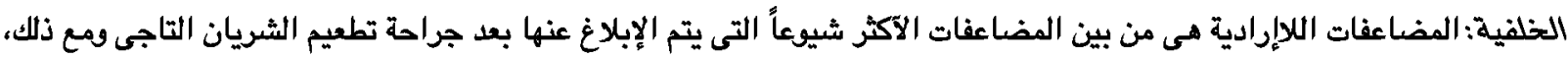

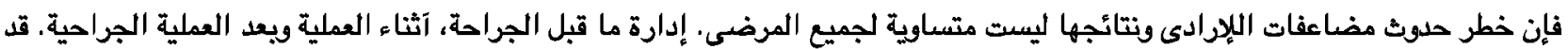

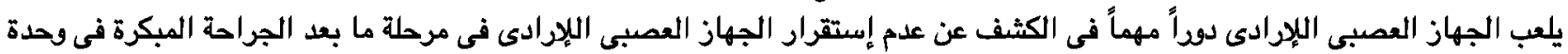

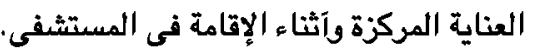

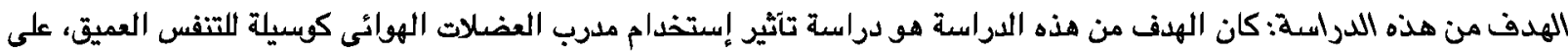
الجهاز العصبى اللإرادى عن طريق تحليل تقلب معدل ضعريات القلب وعدد الإنقبات البطينية المسبوقة، وعلى القدرة الوظيفية من خلال - إختبار المشى لمدة ستة دقائق.

المواد والآساليب: خضع · ع مريضاً من الذكود الذين خضعوا عملية ترقيع الشريان التاجى تتراوح آعمارهم بين · ع و.7 عاماً وتم تعيينهم

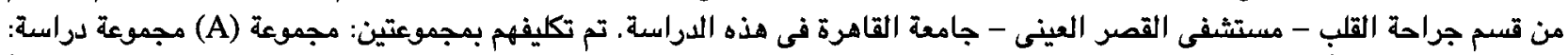

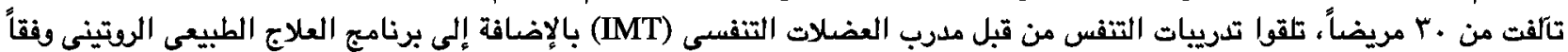

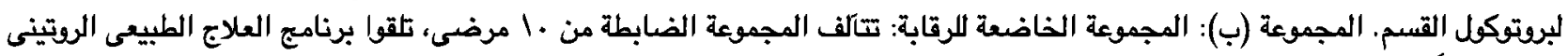

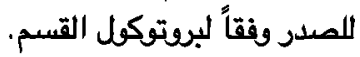

$$
\text { بلدآ البرنامج فى اليوم الآول بعد الفطام من جهاز التنفس الصناعى وينتهى فى يوم الضرج. }
$$

النتائج : يوجد فروق ذات دلالة إحصائية في معدل تقلب نبضات القلب وإختبار المشى لمدة ستة دقائق داخل نفس المجموعة وفى المجموعتين

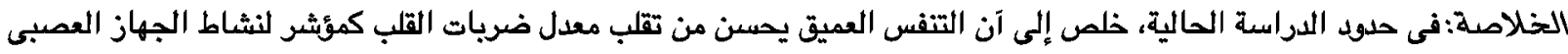

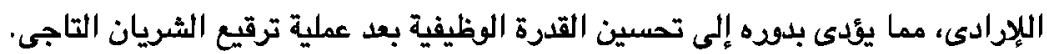

